\title{
Cooperação Científica Internacional: Estilos de Atuação da Fundação Rockefeller e da Fundação Ford
}

Lina Faria

Maria Conceição da Costa

\begin{abstract}
“Dificilmente se pode encontrar uma instituição tão assemelhada à face mitológica de Jano como a ajuda externa" (Hirschman, 1971, tradução das autoras)
\end{abstract}

\section{INTRODUÇÃO}

\begin{abstract}
A conformação de campos científicos tem sido, em grande medida, uma tarefa realizada por algumas agências de fomento, denominadas internacionais. As agências internacionais foram adquirindo prestígio, cada vez mais reconhecidas como atores importantes em seus países de origem e também fora deles, influenciando a formação de distintas áreas do conhecimento.

A atuação dessas agências, em grande medida, tem se dado a partir da idéia de cooperação internacional, o que na teoria significa troca de saberes entre os financiadores e os receptores da doação, e na prática um interesse no estado da arte da ciência em diferentes países. A cooperação internacional é um fenômeno em expansão, isto é, cresce com as atividades científicas. Pesquisadores de países em desenvolvimento têm se beneficiado dessa cooperação na medida em que a colaboração envolve um número significativo de programas - desde pesquisas na área de ciência, de tecnologia, conferências e reuniões científicas, compras de equipamentos, formação profissional e a concessão de bolsas de estudos para instituições estrangeiras.
\end{abstract}

DADOS - Revista de Ciências Sociais, Rio de Janeiro, Vol. 49, n-1, 2006, pp. 159 a 191. 
Desde contribuições clássicas como as de Jaguaribe (1967) e Hirschman (1971) até estudos mais recentes (Velho, 1997), têm-se afirmado que a cooperação internacional pode favorecer a transferência de recursos materiais e humanos dos países desenvolvidos para os países em desenvolvimento. Esta forma de incentivo é importante para a instalação de um setor científico em países menos favorecidos. Além disso, a cooperação a partir de blocos regionais, ou seja, a implementação de programas de cooperação científica e tecnológica entre países de uma determinada região, vem sendo uma prática incentivada pelas agências internacionais com o objetivo, segundo a autora, de tentar solucionar deficiências individuais, a partir do desenvolvimento conjunto das economias e com benefícios eqüitativamente distribuídos entre as nações envolvidas na cooperação (idem).

A cooperação científica apontada como ferramenta necessária para o avanço da ciência no mundo contemporâneo, especialmente pós-Segunda Guerra Mundial, foi mudando seu estilo de atuação, especialmente nas últimas três décadas. A cooperação internacional tem se pautado por estilos de ação diferenciados conforme os interesses das agências de fomento e a correlação de forças internas nos países onde atuam. É desta forma que hoje se evidencia uma cooperação mais voltada para programas de desenvolvimento sustentável dos recursos naturais, saúde reprodutiva, direitos humanos, habitação, além de campanhas de prevenção contra o Vírus da Imunodeficiência Adquirida HIV / AIDS, tentando incentivar a participação e o desenvolvimento de comunidades locais. Esta é uma orientação inaugurada por agências internacionais como a Fundação Ford, como se verá mais adiante.

As agências fundadas no começo do século XX, como a Fundação Rockefeller, pautaram-se por um estilo de atuação voltada, em grande medida, para a doação, sem fins lucrativos, em atividades científicas, em universidades e institutos de pesquisa, diante do crescimento da importância e das necessidades da ciência e da tecnologia. As diferentes ênfases antes e pós-guerra são a marca da atuação da Fundação Rockefeller. As áreas de saúde pública, medicina e educação são praticamente exclusivas até o período da guerra. No pós-guerra há uma mudança de orientação. A partir daí, o apoio às ciências físico-químicas e naturais aumenta progressivamente, assim como a área da agricultura (Schwartzman, 2001)1. Entre os anos de 1950 e 1980, a Rockefeller pauta sua atuação por uma orientação política conservadora, promovendo centros e programas de controle e planejamento populacio- 
nal, como o Population Council. De modo geral, a Fundação guardava ou mantinha uma visão conservadora dos processos de mudança social.

A partir do final da Segunda Guerra Mundial, é a Ford - também uma das mais importantes fundações americanas na área de medicina e ciência -, entre outras agências de fomento, quem inaugura um novo estilo de doação e de intervenção, por assim dizer, mais participativo e democrático de financiamento à pesquisa. A Ford vai assumindo uma posição de liderança na liberação de recursos em diferentes campos de atuação e em vários países dos continentes americano, africano e asiático. $\mathrm{O}$ apoio à área de administração pública passa a ser um dos grandes interesses da Ford. $\mathrm{O}$ apoio irrestrito da Fundação à diversidade social e à participação democrática manifesta-se por meio de financiamento de programas voltados para abordagens que privilegiam, por exemplo: questões de gênero; saúde da mulher; modelos de desenvolvimento sustentável; programas de saúde; reforma educacional; habitação; violência, questões étnicas e raciais; desigualdade social; meio-ambiente e recursos naturais (biodiversidade); movimentos sociais. De modo geral, incentivo a programas liderados por comunidades locais e promoção de políticas públicas. São privilegiados programas que refletem os interesses dos movimentos sociais em países diversos.

Este estilo de doação, mais participativo, que vê a ciência como uma construção social, isto é, realizada por diferentes atores - não apenas universidades e centros de pesquisa, mas agências não-governamentais e grupos participativos locais - e, principalmente, mais preocupado com as realidades sociais, passou a ser o modelo de atuação das agências internacionais no pós-guerra. A partir deste momento, é possível notar, portanto, uma mudança de orientação da ótica das agências de fomento em direção à questão social (Costa, 2004).

Ao discutir, no final dos anos 1960, sobre as "condições de validez" da assistência técnica internacional, Hélio Jaguaribe (1967) chama a atenção para duas exigências específicas no campo da cooperação internacional. A primeira, segundo o autor, refere-se à prioridade que se deve conceder à educação e ao treinamento, em todos os níveis. A segunda, tão importante quanto a primeira, é a liberdade de escolha dada ao país receptor. A ajuda deve ser solicitada e selecionada pelo país que está recebendo a doação ${ }^{2}$. Para Jaguaribe (idem:83-84), é desta forma que os programas de assistência científica internacional são capazes de promover transformações sociais. 
É nesse quadro de mudanças e transformações que se destaca a Fundação Ford. A história da Ford confunde-se com as das agências filantrópicas internacionais as quais se institucionalizam dentro do modelo de desenvolvimento para os países não industrializados (ver Arnove, 1980; Miceli, 1993). Desde o início de suas atividades em países da Ásia, África e América Latina, a Ford vem realizando parcerias com inúmeras instituições na implementação de iniciativas de desenvolvimento, desde a Revolução Verde e a atenção às questões de gênero e população, até o fortalecimento de novos modelos para o desenvolvimento social.

Nos anos 1980, a Fundação Rockefeller também se dedicou a investimentos nessas áreas. No Brasil, a Rockefeller voltou a investir em programas de saúde, como, por exemplo, os de prevenção contra a AIDS/SIDA. Mas, além desses programas, financia escritórios para a capacitação de lideranças (investimentos para Organizações Não-Governamentais - ONGs e profissionais de aparelhos de Estado) para atuarem na preservação do meio ambiente, promovendo o desenvolvimento sustentável e formando recursos humanos capazes de formular acordos internacionais para cumprirem estes objetivos (Rockefeller Foundation, Relatório Anual, 1989).

Tendo como ponto de partida as mudanças vividas por essas agências e a natureza do relacionamento destas nos países por onde passaram, o objetivo deste artigo é mostrar contrastes e eventuais paralelos entre os estilos de ação da Fundação Rockefeller e da Fundação Ford. Estas duas agências foram responsáveis pela criação de áreas de conhecimento, em diferentes países do mundo (Brasil, China, Índia, entre outros), com base em padrões de atuação e de intervenção por vezes distintos, mas ainda assim marcantes.

Finalmente, o objetivo deste artigo é entender a maneira como essas fundações readequaram suas agendas em função da presença de novos atores e, ainda, como introduziram novos problemas sem, necessariamente, mudarem seus padrões de intervenção de modo radical.

\section{A ATUAÇÃO DIVERSIFICADA DA FUNDAÇÃO ROCKEFELLER}

No início do século XX, a família Rockefeller (John D. Rockefeller e Rockefeller Jr.) decidiu criar uma organização que incorporasse as instituições pertencentes à família - Rockefeller Institute for Medical Research, General Education Board e Sanitary Commission for the Erradication of Hook- 
worm - dando origem à Fundação Rockefeller³, em 1913 (Collier e Horowitz, 1976:60-65). O modelo de "filantropia em larga escala" da Fundação Rockefeller compreendia a atuação nas áreas das ciências naturais, saúde pública e educação superior, que eram consideradas fundamentais para o desenvolvimento das sociedades modernas ou em vias de modernização. Nessa época, a fortuna dos Rockefeller havia sido estimada em US $\$ 1$ bilhão, metade representada pelo valor negociável de algumas de suas ações de minas de ferro, em Minnesota, e de carvão, no Colorado, além de ações de várias ferrovias (Howe, 1982:27).

Em um primeiro momento, a Fundação Rockefeller visou dar continuidade à tarefa de erradicação da ancilostomíase, empreendida desde 1909 pela Sanitary Commission for the Erradication of Hookworm no Sul dos Estados Unidos. A experiência adquirida nesta região foi importante para organizar, posteriormente, as atividades que seriam implementadas pela Rockefeller em países da Ásia, Europa e América Latina, a partir de 1916 .

Entre os países, além do Brasil, que contaram com a cooperação da Rockefeller estavam: na América do Sul - Equador, Argentina, Colômbia, Chile, Paraguai, Peru, Uruguai, Venezuela; na América Central - Costa Rica, Cuba, Guatemala, Haiti, Nicarágua, Panamá, El Salvador, Jamaica, Trinidad e Tobago, Granada. Na Ásia, a Rockefeller atuou no Ceilão, Índia, Malásia, Coréia e Tailândia. Na China e no Japão, a Fundação chegou a permanecer por quase 60 anos. No Oriente Médio, esteve no Iraque, na Turquia, em Israel e no Líbano. Alguns países do continente africano também receberam o apoio da Rockefeller. As atividades chegaram a se estender até a Europa, no período entre as duas grandes guerras: a Inglaterra, logo após o fim da Primeira Guerra, e em seguida outros países do Continente, como a França, Espanha, Portugal e Albânia. O Canadá recebeu auxílio a partir de $1920^{4}$.

É possível identificar dois momentos importantes da atuação da Fundação Rockefeller, em escala global. O primeiro iniciado em 1913 dava ênfase à medicina e ações em saúde pública. Durante as décadas de 1920 e 1930, a Rockefeller direcionou suas atividades para pesquisa e controle de doenças infecciosas como a ancilostomíase, a febre amarela e a malária. Um segundo momento que se consolidou no final dos anos 1940, mais precisamente com o fim da Segunda Guerra Mundial, ligou-se ao desenvolvimento do ensino médico, das ciências físicas e biológicas e da agricultura (Cueto, 1994; Marinho, 2001). Uma das priori- 
dades da Fundação foi então a concessão de bolsas de estudos nas universidades dos Estados Unidos. A possibilidade de treinamento no exterior foi um dos aspectos da política científica da Fundação Rockefeller. $\mathrm{O}$ acesso de pesquisadores de vários países a universidades norte-americanas foi aproveitado tanto pelos profissionais da área biomédica quanto, mais tarde, por cientistas que atuavam no campo da genética, da física, da biologia, da zoologia e da agronomia.

No plano mundial, a Fundação Rockefeller teve uma atuação pioneira na concessão de bolsas de estudos para a ciência médica e a saúde pública. Entre 1917 e 1962, a Fundação Rockefeller concedeu cerca de 1.800 bolsas de estudo para pesquisadores latino-americanos. O Brasil (443 bolsas) e o México (359 bolsas) foram os países que mais receberam bolsas nas áreas da medicina e das ciências naturais. Em terceiro lugar, a Colômbia (264 bolsas), seguida do Chile (214 bolsas) e da Argentina (127 bolsas). O programa de bolsas também contemplou pesquisadores de outros países na América Latina (Paraguai, Peru, Venezuela), Europa (sobretudo França, Bélgica, Espanha, Itália, Portugal e Romênia), Ásia e África ${ }^{5}$. É importante ressaltar que, nesse mesmo período, a Fundação John Simon Guggenheim - também uma das mais importantes fundações americanas na área de medicina e ciência - concedeu cerca de 610 bolsas de estudos para profissionais latino-americanos, ou seja, menos da metade das bolsas oferecidas pela Fundação Rockefeller (Cueto, 1994:x-xi).

A ampla dimensão das atividades da Fundação Rockefeller desdobrou-se em ações diferenciadas em vários continentes, conforme seus interesses e a correlação de forças internas nos países onde a instituição norte-americana atuou. No Brasil, por exemplo, para lograr êxito, a Rockefeller teve de ajustar seus objetivos e modelos de atuação às condições históricas, culturais e sanitárias do país. Em particular, teve de adaptar-se às estratégias de modernização política e social que já estavam em curso quando as missões médico-sanitárias da Rockefeller aqui chegaram (Castro Santos, 1989; Castro Santos e Faria, 2003).

Entre os anos de 1920 e 1960, a Fundação Rockefeller ajudou a construir e implantar uma extensa rede de instituições científicas que propiciaram a difusão e a consolidação de um modelo de ciência. Neste sentido, é correto afirmar que a atuação da Rockefeller pode ser vista como decisiva na institucionalização da ciência em escala mundial. A Rockefeller incentivou a criação de faculdades médicas, de novas disciplinas nas 
áreas de patologia, anatomia, histologia e microbiologia, e de institutos de higiene, escolas de saúde pública e enfermagem para formação de profissionais na área da saúde. Foi assim na Inglaterra (London School of Higiene), na China (Peking Union Medical College), em Cuba (Escola de Medicina da Universidade de Havana) e no Brasil (Faculdade de Medicina e Cirurgia de São Paulo ${ }^{6}$, Instituto de Higiene de São Paulo 7 , Escola Anna $\left.\mathrm{Nery}^{8}\right)$. A Fundação apoiou também pesquisas no campo da fisiologia no Peru e na Argentina, nos anos 1930 e 1940 (Cueto, 1994: 4-6). A Rockefeller imprimiu àquelas instituições sua orientação pedagógica, marcada por critérios universalistas, dedicação integral dos professores, ênfase na pesquisa e no laboratório, definição de padrões técnicos de trabalho para a enfermagem hospitalar e de saúde pública e difusão de um enfoque operacional para a organização das campanhas sanitárias (Castro Santos e Faria, 2003). Deve-se acrescentar, ainda, a sólida parceria com a medicina e as ciências naturais da Universidade de São Paulo - USP, inclusive em relação à Faculdade de Medicina em Ribeirão Preto ${ }^{9}$, nas décadas de 1940 e 1950 . Nesta fase, as instituições que mais se beneficiaram desta política de incentivo ao ensino foram, no México, o Instituto Tecnológico de Monterrey; no Brasil, a USP, Campus de Ribeirão Preto; e na Colômbia, a Universidade do Valle.

Na América Latina o aprofundamento das relações com a Fundação Rockefeller foi o resultado de desdobramentos durante e após a Segunda Guerra ${ }^{10}$. A partir desse momento, houve uma reestruturação das atividades financiadas pela Fundação Rockefeller nos países latino-americanos, e, em especial, no Brasil. Segundo Marinho, "ao lema anterior de promover o bem da humanidade, acrescentou-se a nova meta de promover o progresso do conhecimento científico" (2001:29). A atuação da Rockefeller caracterizou-se por um estímulo às ciências físico-químicas e naturais (sobretudo a genética, a física e a biologia), sobrepondo-se à primeira fase nitidamente voltada para a saúde públi$\mathrm{Ca}^{11}$. Esta nova orientação possibilitou uma maior diversificação das atividades da Rockefeller. Entre os anos de 1940 e 1970, a Fundação investiu fortemente na área da genética, particularmente na pesquisa agrícola. O suporte à agricultura significou uma expansão de suas atividades em vários países.

Nesse contexto, um dos mais importantes capítulos da história da filantropia em larga escala da Fundação Rockefeller foi a chamada "Revolução Verde" no México. Entre os anos de 1943 e 1965, a Fundação investiu cerca de US\$13 milhões em equipamentos, pesquisas, bolsas de 
estudos e treinamento profissional. O uso pelos agricultores de novas tecnologias agrícolas provocou um profundo impacto na produtividade, criando condições para o aumento da produção de alimentos no país. Este trabalho pioneiro foi responsável pela aplicação de ciência e tecnologia na produção de arroz e milho (Fitzgerald, 1994).

O Brasil também participou desse processo de modernização da agricultura, incentivado pela Fundação, que liberou recursos significativos para a criação ou desenvolvimento de áreas científicas no país. Tal fato se deu especificamente com a genética. A USP foi o local escolhido como um lugar que deveria receber total apoio. A Rockefeller apoiou programas de pesquisas, concedeu bolsas de estudos para o exterior e financiou a compra de equipamentos de última geração.

\section{OS ANOS 1940 E A REDEFINIÇÃO DOS CAMPOS DE ATUAÇÃO: 0 APOIO À GENÉTICA NO BRASIL}

Como se disse anteriormente, no pós-guerra o foco de atuação da Rockefeller declina da saúde pública e direciona-se para o fomento na área das ciências naturais. Na América Latina, o Brasil foi um alvo especial desta política. Tal deslocamento favoreceu diretamente a institucionalização de grupos e linhas de pesquisa na USP, duas das quais a física e a genética são exemplo. Vejamos o caso da genética.

Embora estudos na área da genética tenham tido início em meados dos anos 1920, nas cadeiras de zootecnia e agricultura da Escola Superior de Agricultura Luiz de Queiroz, em Piracicaba, com Carlos Teixeira Mendes $^{12}$, Otávio Domingues e Salvador de Toledo Piza Jr. ${ }^{13}$, foi a partir dos primeiros anos de 1930 que as pesquisas nesta área ganharam impulso no país.

Nesse período três grupos se destacaram: um primeiro liderado por Carlos Arnaldo $\mathrm{Krug}^{14}$, no Instituto Agronômico de Campinas, um segundo organizado por Friedrich Gustav Brieger ${ }^{15}$ na Escola Superior de Agricultura Luiz de Queiroz, em Piracicaba, e o grupo da USP chefiado por André Dreyfus ${ }^{16}$, chefe do Laboratório de Biologia Geral da Faculdade de Filosofia e primeiro professor de biologia da recém-criada USP. Dreyfus desempenhou, segundo Glick (1994), um papel importante na institucionalização da genética no Brasil.

Em 1932, Carlos Arnaldo Krug iniciou um programa de genética aplicada à agricultura no Instituto Agronômico, com o objetivo de melhorar 
produtos como o café, o trigo, o fumo e o milho. No ano seguinte, foi criada a cadeira de genética, "que tinha o objetivo claramente aplicado de formar especialistas com conhecimentos básicos de melhoramento e técnica experimental" (Schwartzman, 2001:180-186). Na Escola Superior de Agricultura Luiz de Queiroz, em Piracicaba, as pesquisas na área da genética tiveram continuidade com Friedrich Gustav Brieger, chefe do Departamento de Genética. Em 1934, a Escola foi incorporada à recém-criada USP. Brieger queria implantar no departamento o regime de tempo integral para a pesquisa e docência "para realmente transformar uma escola de ensino numa instituição universitária". A implantação do regime de tempo integral "foi o início do novo desenvolvimento da Luiz de Queiroz que se tornou [...] a melhor Escola de Agronomia da América Latina" (Brieger, 1985:6-18 apud Marinho, 2001).

Estes três cientistas - Krug, Brieger e Dreyfus - faziam parte de um grupo seleto na área da genética no Brasil. Esses foram responsáveis por importantes pesquisas, além da formação de novos pesquisadores. Dreyfus, assim como Brieger, também era favorável à introdução do regime de tempo integral para pesquisa e docência. Em 1938, Dreyfus conseguiu introduzir em seu departamento o tempo integral e começou a negociar a contratação de profissionais estrangeiros com boa formação na área. Note-se a referência à dedicação em tempo integral dos profissionais, regime de trabalho que a Fundação Rockefeller julgava imprescindível.

O contato de Dreyfus com Harry Miller Jr. - diretor-associado da Divisão de Ciências Naturais da Fundação Rockefeller e principal articulador das ações da instituição norte-americana no Brasil nas décadas de 1940 e 1950 - criou condições favoráveis para a vinda de pesquisadores estrangeiros para atuarem no Departamento de Biologia Geral da USP. Segundo Thomas Glick (1994), a implantação definitiva da genética no Brasil ocorreu quando Theodosius Dobzhansky ${ }^{17}$ veio para o país a convite de André Dreyfus, com o apoio da Fundação Rockefeller, para trabalhar no Departamento de Biologia. Dobzhansky já havia manifestado a Harry Miller Jr. seu interesse pelo estudo da genética em países da América Latina.

As doações da Fundação Rockefeller para o Departamento de Biologia estenderam-se até a década de 1960. A instituição norte-americana financiou equipamentos e concedeu várias bolsas de estudos para pesquisadores brasileiros. Nas palavras de Glick, "[...] no total, este proje- 
to representou um modelo de sucesso na história da ciência latino-americana e ilustra a intervenção criativa de uma fundação americana no desenvolvimento científico de um país" (Glick, 1994:149). Na década de 1960, existiam, ainda segundo esse autor, cerca de 12 centros de pesquisa em genética no país, em que se destacavam São Paulo, Rio de Janeiro, Porto Alegre, Campinas (idem:159).

O estudo da implantação da genética no Brasil permite mostrar o papel da instituição norte-americana na institucionalização da pesquisa genética no país. A experiência nesta área indica a participação da Rockefeller no desenvolvimento científico brasileiro, que data desde os inícios dos anos 1920 do século passado, como procuramos mostrar ao longo do $\operatorname{artigo}^{18}$.

\section{A ATUAÇÃO INTERNACIONAL DA FUNDAÇÃO ROCKEFELLER}

No início dos anos 1950, a Fundação Rockefeller começou a preocupar-se com o crescimento populacional, voltando sua atenção para a promoção de controle demográfico. Em 1952, John D. Rockefeller (neto) criou o Population Council, para um melhor entendimento dos problemas relativos ao crescimento populacional dos países subdesenvolvidos. Para os líderes da instituição norte-americana, as taxas constantes de crescimento constituíam um dos principais obstáculos ao desenvolvimento socioeconômico daqueles países. Embora o Population Council tenha sido criado no início dos anos 1950, o Conselho ganhou força nas décadas de 1960 e $1970^{19}$. Nesta época, a Rockefeller passou a investir em pesquisas que tinham como objetivo um melhor entendimento dos fatores relacionados ao crescimento demográfico, além de programas de planejamento familiar, e de formação de especialistas na área da reprodução.

O Population Council foi concebido por John D. Rockefeller como uma organização internacional, sem fins lucrativos. Por cerca de duas décadas, o Conselho voltou-se para a difusão de noções e programas de caráter neomalthusianos, em que o crescimento populacional parecia constituir um fator decisivo de atraso social e econômico. Fatores estruturais - como a reforma agrária - eram considerados importantes frentes de atuação, mas politicamente inviáveis. Com o surgimento de movimentos sociais ligados a questões de gênero, a própria noção de "planejamento familiar" ganhou outro sentido, perdendo seu caráter autoritário e impositivo. O conceito de "saúde reprodutiva" conquis- 
tou um espaço definitivo nos programas da Fundação. Atualmente, a instituição conduz pesquisas em três áreas principais: biomédica, saúde pública e ciência social, relacionadas a pesquisas na área de saúde reprodutiva. Localizada na cidade de Nova York, com um escritório em Washington, DC, a agência promove e financia programas globais na área de saúde reprodutiva e prevenção e tratamento de doenças sexualmente transmissíveis, particularmente doenças congênitas, sífilis e infecções cervicais, tais como blenorragia.

$\mathrm{Na}$ área das artes e humanidades, o Laura Spelman Rockefeller Memori$a l^{20}$, criado em 1918, financiou eventos de música, dança, pintura e fotografia. Atualmente, o Programa de Artes e Humanidades da Rockefeller funciona como um veículo de difusão cultural, que tem como objetivo principal incentivar artistas da Europa, da África, da Ásia e da América Latina, em diferentes dimensões da atividade cultural. O objetivo do Programa é promover talentos regionais e difundir seus trabalhos. A família Rockefeller financiou a criação do Museu de Arte Moderna de Nova York, "MoMA", um dos maiores e mais importantes acervos de arte contemporânea. No Brasil, o Museu de Arte de São Paulo-MASP foi impulsionado por David Rockefeller, que patrocinou a compra de quadros para o acervo do famoso museu paulista (ver Rockefeller, 2003).

Nos últimos 10 anos, cinco grandes programas têm guiado as ações da Fundação Rockefeller em vários países do Mundo. São eles: "Health Equity" (apoio à produção de vacinas para prevenção e tratamento de doenças típicas de países do Terceiro Mundo, buscando a eqüidade em saúde); "Food Security" (programa de Segurança Alimentar, de apoio ao desenvolvimento de novas variedades agrícolas, com o objetivo de aumentar a produtividade e o acesso ao mercado internacional); "Working Communities", (apoio a comunidades populares, por meio de financiamento em educação e habitação); "Creativity \& Culture" (financiamento na área das artes e humanidades) e "Global Inclusion" (tentativa de amenizar os impactos da globalização em comunidades vulneráveis de países do Terceiro Mundo, apoiando programas de inclusão social) (Rockefeller Foundation, Relatório Anual, 2005).

\section{OS ANOS 1950 E A ENTRADA EM CENA DA FUNDAÇÃO FORD}

A entrada da Fundação Ford no cenário internacional se dá desde os anos 1950. Neste período, a Ford assume um papel de destaque na con- 
dução das atividades científicas e na formação de recursos humanos em escala mundial. Segundo Villar, em 1959 o patrimônio total da Fundação Ford era de cerca de US\$ 3,5 bilhões ${ }^{21}$, seguida da Fundação Rockefeller com um patrimônio de US\$ 648 milhões (Villar, 1964:372374).

A Fundação Ford foi criada em 1936 nos Estados Unidos por Edsel Ford e sua mulher Eleanor Clay Ford, como uma organização filantrópica, sem fins lucrativos. Inicialmente suas atividades se direcionaram para ações dentro do próprio país. A Ford funcionou como organização filantrópica local no Estado de Michigan até expandir-se, em 1952, para se tornar uma fundação de alcance nacional e internacional. Os recursos foram doados por Henry ${ }^{22}$ e Edsel Ford por meio de ações da Companhia Automobilística Ford - Ford Motor Company 23. O ano de 1947 foi importante para a instituição. Henry Ford deixa uma herança que fortalece o perfil financeiro da Fundação Ford. Em 1948, Henry e Edsel Ford haviam falecido, e Henry Ford II assume a direção da Ford Motor Company e da Fundação Ford (Nielsen, 1996).

Nessa época, Henry Ford II manifesta vontade de trabalhar somente com a Ford Motor Company, e Eleanor Clay Ford sugere, então, a criação de um Comitê para determinar a estrutura, os objetivos e as prioridades da Fundação. Os membros são escolhidos, e, em 1952, Paul Hoffman é eleito o primeiro presidente da Ford. Um ano depois é substituído por Robert Maynard Hutchins (Universidade de Chicago), defensor de liberdades civis, que atraía "como um pára-raio" os ataques da direita anticomunista sobre a Fundação. Como resultado, a Ford sofreu investigações pelo Congresso e campanhas da mídia contra a sua direção, mas foi a partir desse momento que a expandiu suas doações para países da Ásia, África e América Latina (idem).

De acordo com o relatório anual da Ford de 1963, a decisão de trabalhar fora dos Estados Unidos - com a abertura dos primeiros escritórios na Ásia (Índia, Paquistão, Indonésia) e América Latina - estava fundamentada em três convicções:

“[...] a de que dar solução aos problemas internos dos Estados Unidos seria uma vitória vazia se o resto do mundo continuasse sujeito à 'miséria e às agitações' ; a de que a Fundação Ford dispunha de recursos suficientes para oferecer uma contribuição significativa na solução desses problemas em outros países; e a de que, por ser uma organização independente, não-governamental, ela tinha autonomia para aplicar seus 
recursos em determinados países e na solução de determinados problemas [...]" (Ford Foundation, 1963:2 apud Brooke, 2002:13) ${ }^{24}$.

O estímulo à redução da pobreza e da injustiça social, à promoção da cooperação internacional e ao fortalecimento dos valores democráti$\cos$ foi a marca da atuação da Fundação Ford, em escala mundial. Desde sua criação até os dias atuais, a Ford já investiu cerca de US $\$ 10$ bilhões em programas sociais e educação, saúde reprodutiva e AIDS, justiça social e direitos humanos, meio ambiente e treinamento em áreas, tais como a agricultura, além da concessão de bolsas de estudos para as universidades dos Estados Unidos e de outros países ${ }^{25}$.

Entre os anos de 1952 e 1983, a Fundação investiu cerca de US\$ 260 milhões em programas de estudos de população nos Estados Unidos e em outros países, assim como em programas de prevenção contra a HIV / AIDS e naqueles de formação de especialistas na área da reprodução ${ }^{26}$. Lembremos aqui, como apontamos anteriormente, que nos anos 1980, a Fundação Rockefeller também passa a financiar programas na área de prevenção contra a HIV / AIDS e na de formação de especialistas na área de saúde reprodutiva.

Atualmente, as áreas de atuação da Fundação Ford são as seguintes: Desenvolvimento Sustentável; Saúde Reprodutiva; Direitos Humanos; Educação e Governo; e Sociedade Civil ${ }^{27}$. O Programa de Desenvolvimento Sustentável, por exemplo, procura promover políticas, práticas e capacidades institucionais que contribuam para o uso sustentável dos recursos naturais, visando à melhoria das condições de vida de populações carentes. O Programa também busca promover o envolvimento da população no debate das políticas públicas e estimular encontros entre comunidades, profissionais e responsáveis pelas políticas públicas para intercambiar experiências e estimular a melhoria das intervenções a favor do desenvolvimento sustentável.

O Programa de Saúde Reprodutiva - uma área em que a Fundação Rockefeller também participa ativamente - incentiva estudos de políticas públicas e iniciativas que forneçam às mulheres os recursos para entender, articular e enfrentar de forma efetiva suas necessidades em saúde reprodutiva. As ações desse Programa envolvem a pesquisa aplicada em ciências sociais sobre questões tais como aborto clandestino, mulheres e HIV / AIDS, além do treinamento em serviços multidisciplinares de saúde e ciências sociais com ênfase na maior compreensão das relações de gênero e sexualidade. Um dos objetivos maiores do 
Programa é promover debates sobre ética, direitos humanos e saúde reprodutiva os quais ajudem a formular princípios norteadores para as relações de gênero, tolerância moral e respeito por populações socialmente vulneráveis (Ford Foundation, Relatório Anual, 2004).

Na área de Direitos Humanos, as ONGs foram e continuam sendo as maiores beneficiárias da Ford. Na "sua luta em prol da redemocratização", a Fundação decidiu apoiar programas sociais tais como: reforma agrária, direitos da mulher, direitos dos índios e luta contra o preconceito racial (Brooke, 2002:25). Um dos principais objetivos desse Programa é estender a todos os membros de uma comunidade o acesso à justiça e à cidadania democrática, com enfoque especial aos grupos mais vulneráveis - aos direitos da mulher, do negro e dos grupos indígenas (Adorno e Cardia, 2002).

Os programas de Educação e Governo e Sociedade Civil (GCS) foram áreas em que a Fundação Ford se destacou. Há 40 anos, a Ford apóia universidades, ONGs, instituições e centros de pesquisa na área da educação, contribuindo para o desenvolvimento do ensino superior em seus programas internacionais. Esse Programa foi criado no início dos anos 1980, como um esforço para tentar solucionar questões na área de administração pública, mas desde a década de 1950 a Ford vem apoiando estudos sobre problemas urbanos (violência, drogas, pobreza, habitação), políticas públicas e movimentos sociais.

Na parte dedicada à administração pública, mostraremos que o pioneirismo nessa área foi da Fundação Rockefeller, que, a partir dos anos 1930, implantou um amplo programa nos Estados Unidos e na Europa. A Rockefeller tinha penetrado em um espaço, que continuaria a ser explorado até o final dos anos 1950. Quando cessaram as contribuições da Fundação à área da administração pública, a Ford foi gradativamente assumindo o financiamento ao Programa.

Vejamos, a seguir, o apoio da Fundação Ford às Ciências Sociais no Brasil.

\section{O APOIO DA FUNDAÇÃO FORD À EDUCAÇÃO - O BRASIL E AS CIÊNCIAS SOCIAIS}

Na década de 1960, a Ford iniciava suas atividades em países da América Latina, apoiando pesquisas na Argentina, na Colômbia, no Chile, no Brasil e no México. No Brasil, a Ford abre um escritório em 1962 no 
Rio de Janeiro e, logo em seguida, concede suas primeiras doações a universidades públicas e instituições do governo brasileiro. O campo do ensino superior foi, desde o começo, uma área fundamental das atividades da Ford no país. Os primeiros esforços foram direcionados para áreas tais como engenharia, agronomia, administração e economia. Aos poucos, as ciências sociais tornaram-se um campo privilegiado de ação da Fundação. A Ford incentivou os primeiros programas direcionados à pós-graduação em várias universidades brasileiras, como o de Antropologia do Museu Nacional e os cursos de Sociologia e Ciência Política do Instituto Universitário de Pesquisas do Rio de Janeiro - Iuperj. Desse momento em diante, a instituição investiu cerca de US \$ 350 milhões em atividades que vão desde ensino das ciências a reforma da política (Brooke, 2002:13-53).

O escritório do Rio de Janeiro está entre os mais antigos dos 15 que a Fundação Ford mantém em diversas regiões do mundo ${ }^{28}$, para permitir parcerias de trabalho mais próximas com os indivíduos e as instituições que recebem seu apoio. Anualmente, a Ford distribui cerca de US\$ 13 milhões em doações para centros de pesquisa e diversas instituições brasileiras que trabalham em áreas prioritárias. "Como nas demais regiões, o Escritório do Brasil tem sido fonte de apoio financeiro a pessoas e organizações inovadoras comprometidas com o progresso humano, a consolidação da democracia e a redução da pobreza e da injustiça" (Ford Foundation, Relatório Anual, 2004). Através de doações para pesquisa e treinamento em áreas tais como agricultura, estudos demográficos e ciências sociais, o escritório do Rio de Janeiro colaborou ativamente na criação de várias instituições de pesquisa e associações acadêmicas de prestígio internacional.

A Ford ficou conhecida no Brasil principalmente por sua atuação no ensino superior, na área das ciências sociais. Segundo Miceli (1993:41), uma das mais importantes realizações da Fundação Ford no continente latino-americano e, em especial no Brasil, teria sido justamente a criação de uma comunidade acadêmica no campo das ciências sociais.

A Ford aplicou recursos em projetos que contribuíram diretamente para a melhoria de instituições de ensino, através do incentivo à pesquisa científica e ao treinamento profissional. Os maiores investimentos no período entre as décadas de 1960 e 1980, da ordem de 800 mil dólares, foram doados a Capes para repasse de bolsas a estudantes em diversas áreas, entre elas, a de Ciências Sociais ${ }^{29}$. Em contínuo contato com cientistas sociais brasileiros, a Ford conseguiu visualizar as mudanças que vinham afetando as ciências sociais e, em conjunto com os 
cientistas brasileiros, soube definir algumas das suas principais linhas de atuação (Campos, 2002). Segundo Campos, antes da presença da Fundação Ford no Brasil, dificilmente se poderia dizer que existisse um ambiente intelectual em âmbito nacional. Foi no quadro das transformações das décadas de 1960 e 1970 que a Ford definiu sua atuação. $\mathrm{O}$ apoio da Ford à criação e financiamento de instituições de pesquisa como o Centro Brasileiro de Análise e Planejamento - Cebrap, Centro de Estudos de Cultura Contemporânea - Cedec e Instituto de Estudos Econômicos, Sociais e Políticos de São Paulo - Idesp, além do apoio a Associações de Pós-Graduação e Pesquisa como a Associação Nacional de Pós-Graduação e Pesquisa em Ciências Sociais - Anpocs e a Associação Brasileira de Empresas de Pesquisa - ABEP, significou um reforço fundamental à pesquisa social no Brasil. O objetivo era estreitar a colaboração entre esses centros de pesquisa e as universidades, além de criar equipes interdisciplinares e desenvolver pesquisas voltadas para questões de ordem social. O apoio da Ford a essas instituições e, especialmente, o dado a Anpocs, possibilitou a criação de um espaço nacional de debates no país (Brandão Lopes, 1993).

O caso do Cebrap foi particularmente emblemático. Em 1969, a fundação do Cebrap, com recursos da Ford, foi um desafio institucional à intervenção dos militares nas Ciências Sociais da USP (a qual que teve o aval dos grupos de direita nos meios intelectuais e universitários paulistas). O Cebrap logo emergiu como um espaço dos mais expressivos do pensamento social latino-americano ${ }^{30}$, somando forças às novas correntes da intelectualidade no Rio de Janeiro, agrupadas no Iuperj e no Museu Nacional. Ressalte-se que, nos casos assinalados, os recursos da Ford representaram um alicerce financeiro, sobre os quais se sedimentaram os programas de pesquisa (em São Paulo) e de pesquisa e pós-graduação (no Rio de Janeiro).

\section{O PROGRAMA GOVERNO E SOCIEDADE CIVIL E O APOIO À ADMINISTRAÇÃO PÚBLICA}

As Fundações Rockefeller e Ford atuaram em diversas áreas comuns, como procuramos mostrar ao longo do texto. Uma das mais expressivas e que merece atenção especial foi a área de administração pública. A Rockefeller foi pioneira, implantando um amplo programa nos Estados Unidos e na Europa no início dos anos 1930. Em 1948, quando cessaram as contribuições da Rockefeller, a Fundação Ford assumiu o financiamento do programa. 
No início dos anos 1930, a Fundação Rockefeller, através do Spelman Fund of New York ${ }^{31}$ decidiu investir pesadamente em projetos ligados à área de administração pública. Segundo Pierre-Yves Saunier (2000:1), "esta foi a maior tentativa de fundações americanas em organizar um campo que eles estavam começando a explorar, para a Europa e para os Estados Unidos, ao findar da década de 20". A filantropia em larga escala e a atuação diversificada da instituição norte-americana voltavam-se para este novo campo.

Rowland Egger - professor de Ciência Política da Universidade da Virgínia e membro de um pequeno grupo internacional preocupado com pesquisa em administração pública - ficou encarregado de "educar, persuadir e induzir" líderes de várias associações européias a trabalharem em conjunto com os americanos nesta empreitada. Várias associações participaram, entre elas a International Union of Local Authorities - IULA, criado em 1913, e o International Institute of Administrative Sciences - IIAS, criado em 1910, ambas com sede em Bruxelas. Essas associações foram concebidas e organizadas por indivíduos que tinham um forte comprometimento com questões na área de cooperação internacional (científica, econômica e social). Além disso, buscavam soluções para alcançar a paz mundial e para questões sociais em diferentes campos. Durante os primeiros anos de atividades, foram organizados encontros e realizadas importantes conferências que culminaram em uma intensa rede de intercâmbios entre americanos e europeus.

Três áreas principais foram escolhidas pelo Spelman Fund para receberem financiamento: habitação, planejamento urbano e governo municipal. Segundo Saunier, a opção pelos investimentos locais deveu-se: em primeiro lugar, ao fato de que o governo municipal era um ator importante no tocante às técnicas, aos programas e aos gastos governamentais. E em segundo, porque as oportunidades eram vistas como maiores possíveis, pelo fato do governo municipal estar mais sintonizado com a vida dos cidadãos e mais envolvido em "fazer a administração funcionar" (Saunier, 2000:7).

A Universidade de Chicago foi escolhida como sede para encontros e reuniões. O "Grupo de Chicago" 32 - como ficou conhecido - ganhou uma sede própria - The Public Administration Building (Chapin Hall) - no campus da Universidade, graças aos esforços conjuntos do Laura Spelman Rockefeller Memorial ${ }^{33}$ e Spelman Fund of New York. O grupo de Chicago foi o centro da ação do Spelman Fund. Entre os anos de 1929 e 1948, 
recebeu cerca de US\$ 14 milhões para projetos e pesquisas na área de administração pública.

Os objetivos e interesses do Spelman Fund eram amplos em relação à área de administração pública. Saunier (idem) cita um memorando, escrito em 1929, no qual se esclareceu os objetivos do Spelman Fund. De acordo com o memorando,

"[...] o interesse do Spelman Fund não se restringe ao melhoramento de algumas práticas ou funções sociais, tais como saúde, educação e prevenção à criminalidade, mas visa antes uma contribuição em todos os aspectos do bem-estar público, através do crescimento da eficiência, da competência técnica e racional e da busca de propósitos racionais na operação da máquina governamental" (idem:6).

No início dos anos 1950, a Fundação Ford começa a operar nessa área. A Public Administration Clearing House - PACH - que se projetou como uma das mais atuantes associações em administração pública - recebeu cerca de US\$ 1 milhão da Fundação. Em 1948, cessaram as contribuições do Spelman Fund ao grupo de Chicago e a outras associações. No entanto, seus líderes foram habilidosos em criar novas conexões e financiamentos, como se deu com a Fundação Ford um ator importante no cenário mundial e que financiaria - desde os anos de 1950 até os dias atuais - projetos e pesquisas na área de administração pública (ibidem).

Nos anos 1980, a Fundação Ford cria o Programa Governance and Civil Society. Este representa hoje uma parcela importante de seu orçamento para todo o mundo. O investimento em GCS contribuiu para a formação de pessoal, e a pesquisa em administração pública e, indiretamente, para a modernização de setores públicos em vários países no mundo, inclusive no Brasil ${ }^{34}$. Problemas como pobreza, desigualdade de renda, analfabetismo, desemprego, disparidade regional e concentração de terra recebem da Ford tratamento especial.

Nos anos 1990, as doações para a administração pública aumentaram consideravelmente. Vários centros de excelência em universidades e, especialmente, ONGs - que se dedicam a temas e grupos sociais particulares como mulheres, habitação, saúde, violência, emprego e movimentos sociais - receberam doações da Fundação. Ainda hoje, este é um campo privilegiado de sua atuação, tecendo redes de solidariedade com famílias em várias partes do mundo (Índia, África do Sul, Tailândia, Filipinas, Nepal, Zimbábue, Camboja, Quênia, Namíbia, Zâm- 
bia, Madagascar, Colômbia), financiando a construção de novas moradias e, também, a regularização de terras (Ford Foundation, Relatório Anual, 2005).

Nessa mesma época, a Fundação Rockefeller também retoma suas atividades na administração pública e passa a liberar recursos para programas sociais em setores da educação, justiça social, habitação e direitos humanos (Rockefeller Foundation, Relatório Anual, 2002; 2003; 2004; 2005).

\section{COOPERAÇÃO INTERNACIONAL: AINDA UMA CRÍTICA E UMA PROPOSTA ${ }^{35}$}

Ao longo do texto, procuramos mostrar a atuação de duas importantes fundações norte-americanas na organização e criação de campos científicos tanto nos Estados Unidos como em outros países. Procuramos apresentar a natureza de intervenção, os objetivos e a própria organização interna dessas duas agências internacionais. Em todas as frentes de apoio - as dotações, as condições dos acordos de cooperação, as concessões de bolsas de estudos -, a atuação de ambas as fundações foi fundamental na criação de condições autônomas e universalistas para a produção científica e na institucionalização da pesquisa de excelência. O instrumento que possibilitou essas ações foi a cooperação internacional, entendida, de maneira ampla, como a transferência de recursos materiais, técnicos e humanos dos países desenvolvidos para aqueles em desenvolvimento. Este mecanismo tem sido importante para a instalação de um setor científico em países do continente americano, asiático e africano.

Quais teriam sido os interesses e objetivos que incentivaram as atividades sanitárias e científicas da Fundação Rockefeller, em escala mundial, a partir do início do século XX? Quais os propósitos de fundações norte-americanas, como a Fundação Ford, ao carrearem recursos milionários para pesquisa e formação profissional em vários países do mundo?

Sérgio Miceli tece considerações sobre os interesses externos norte-americanos e "a diplomacia responsável por gerenciá-los" (1993:37). Suas reflexões sobre a Fundação Ford cabem, a nosso ver, para entendermos a atuação da Fundação Rockefeller em escala mundial. Do mesmo modo que aquele autor, acreditamos que a brutal cobiça norte-americana em relação às economias dependentes como a brasileira não constitui um fator explicativo ao qual se possa atribuir, seja 
o método de atuação, seja o caráter dos investimentos efetuados pelas Fundações, entre os anos 1910 e o segundo pós-guerra, em vários países no mundo e, em especial, no Brasil. As injunções da política externa norte-americana não conseguem por si só dar conta do envolvimento daquelas Fundações com cientistas e intelectuais latino-americanos, africanos e asiáticos.

Para Luiz Antonio de Castro Santos, uma "teoria da ação", que contemple as grandes fundações ligadas à filantropia científica, deve postular uma relativa independência ou "disjunção" entre os campos da ciência aplicada e da economia (Castro Santos, 2004). Desse modo, só a análise empírica poderá estabelecer a medida na qual os dois campos se afastam ou se confundem, em situações históricas precisas.

As singularidades dos países atendidos (tradições médicas, diversidade cultural, diversidade política, movimentos populares etc.) afetaram enormemente o modo como as relações e interesses das fundações norte-americanas se expressaram na institucionalização da ciência naqueles países. Os integrantes das primeiras missões científicas, tanto da Fundação Rockefeller quanto, mais tarde, da Fundação Ford, foram sensíveis às marcantes diferenças entre os países latino-americanos, africanos e asiáticos e à capacidade de expansão institucional dos sistemas de produção intelectual, científica e acadêmica dos países atendidos.

Os documentos consultados, principalmente aqueles referentes ao período pós-guerra, mostram que a manutenção de governos democráticos e a resistência à expansão comunista figuravam entre as preocupações do governo dos Estados Unidos e dos dirigentes das fundações norte-americanas. Entretanto, a concretização dessas metas genéricas podia passar ao largo de dilemas ou desafios concretos como, por exemplo, a capacidade de expansão institucional autônoma dos sistemas de produção intelectual, científica e acadêmica dos países atendidos (Miceli, 1993:39).

Ainda que interesses comerciais e atividades humanitárias necessariamente não se excluíssem, ao invés de seguir uma pauta impositiva, as instituições científicas norte-americanas procuravam adaptar suas pesquisas e atividades a temas que eram particulares a cada país estrangeiro ${ }^{36}$. Nos países da América Latina em que a Fundação Rockefeller esteve presente, "o pensamento nacionalista influenciou não só na seleção de temáticas, mas também fez com que os cientistas reclamassem para seus países suas próprias instituições, laboratórios e bi- 
bliotecas" (Cueto, 1992:11). É certo que estas experiências não se constituíram somente de êxitos. As parcerias institucionais frutíferas não excluem embates ou lutas simbólicas. Se houve efeitos duradouros e positivos da ação das fundações norte-americanas, estes se concentraram, sobretudo, na capacitação científica e tecnológica dos países em desenvolvimento.

Havia, por certo, uma "forma sutil de controle" que se instalava na relação entre o governo dos Estados Unidos e os dirigentes das fundações norte-americanas com a comunidade científica dos países assistidos, na medida em que os trustees determinavam as áreas que seriam apoiadas e, por conseguinte, a agenda mais geral de temas e objeto (Marinho, 2001). No entanto, de modo geral, tanto a Fundação Rockefeller quanto, mais tarde, a Fundação Ford, defendiam a autonomia do pesquisador na definição de temas e objetos de pesquisa. Essa autonomia se estendia aos bolsistas, os quais tinham liberdade para escolher a instituição onde gostariam de realizar seus estudos. A Rockefeller estabelecia critérios universalistas de mérito - alicerçados na competência acadêmica - na seleção dos candidatos a bolsas de estudos, fugindo à influência de favoritismos (Castro Santos e Faria, 2003).

Na esfera de preparação de recursos humanos no âmbito acadêmico, tanto a Fundação Rockefeller quanto a Fundação Ford tiveram atuação destacada. As primeiras bolsas de estudos foram concedidas pela Rockefeller no início dos anos 1920 na área biomédica. A Fundação Ford concedeu suas primeiras bolsas a partir de inícios de 1960 na área de ciências humanas e sociais e da educação, com a finalidade de oferecer oportunidade e condições de trabalho de investigação a seus bolsistas, quando do regresso aos seus países de origem. Foram períodos férteis e fecundos na qual as instituições investiram intensamente em pesquisa e na formação de profissionais.

Como procuramos indicar ao longo do texto, uma das áreas em que as contribuições da Fundação Rockefeller foram mais significativas foi a biomédica. $\mathrm{O}$ apoio da Rockefeller às ciências biomédicas prolongou-se por várias décadas. Vários países receberam recursos financeiros e humanos para montagem de serviços de saúde, formação profissional e campanhas sanitárias. A atuação da Fundação Rockefeller foi importante não só para o desenvolvimento dos serviços médico-sanitários e científicos em vários países, mas também no tocante à educação médica. Entre os anos de 1916 e 1940, além de promover campanhas sanitárias de combate às endemias, atuou também na promoção 
do ensino médico. Já a Fundação Ford teve participação destacada no apoio às ciências sociais não só no Brasil, mas em outros países latino-americanos, africanos e asiáticos. Ambas as instituições destacaram-se no apoio às áreas de ciências naturais, de educação superior e administração pública.

É importante ressaltar que as mudanças de orientação (por exemplo, no tocante a programas direcionados para projetos de justiça e inclusão social) parecem relacionar-se, por vezes, à presença ou não de familiares dos clãs à frente das fundações. No pós-guerra, os dados indicam uma forte inflexão conservadora no comportamento da Fundação Rockefeller com a entrada de um membro da família na política $\left(\right.$ Nelson Rockefeller ${ }^{37}$. Nesse período, os critérios universalistas de avaliação, seleção e doação passam a ser fortemente afetados por valores político-ideológicos - é o que Castro Santos define como a politização perversa da filantropia científica (cf. Castro Santos apud Marinho, 2001). O conservadorismo passa a ser a marca da atuação da instituição. Entre os anos de 1950 e 1980, a Rockefeller pouco investiu em programas sociais, salvo se denominarmos "social" a preocupação com o crescimento da população no Terceiro Mundo, o que seria discutível. No caso da Fundação Ford, é válido assinalar que a abertura para programas ligados a temas da cidadania e minorias sociais ocorre justamente quando Henry Ford II deixa a direção da Fundação, em 1952, passando a instituição a ser dirigida por um grupo preocupado com as questões das liberdades civis (Nielsen, 1996).

É possível dizer que a cooperação internacional favoreceu a capacitação científica e tecnológica nos países em desenvolvimento. Ao discutir sobre os argumentos contrários e favoráveis ao investimento externo norte-americano, Hélio Jaguaribe (1967:77) diz que os Estados Unidos tinham duas alternativas: "ou se encaminhar no sentido da preservação e do fortalecimento das estruturas nacionais dos países subdesenvolvidos, embora não em sua forma e limites atuais, ou se dirigir no sentido da completa supressão destes últimos". No caso brasileiro, diríamos que a Rockefeller teve um papel de "preservação e fortalecimento" até pelo menos os anos da Segunda Guerra. Após o Golpe de 1964, é a Ford quem assume um papel de contrapeso às inclinações antidemocráticas e de exclusão social do regime militar. Essas questões da preservação das estruturas nacionais são de grande importância, pois, ainda segundo Jaguaribe, a assistência técnica só tem valor real e duradouro quando constitui parte de um esforço nacional no sentido daquela preservação. No que tange às instituições doadoras, a coope- 
ração internacional só adquire reconhecimento quando se baseia no respeito pelas estruturas nacionais dos países receptores. Dentro dessas possibilidades, haverá sempre um amplo leque de alternativas e modelos de cooperação.

Tanto Jaguaribe (1967) como Hirschman (1971), em seus estudos clássicos, apontaram os limites e possibilidades da cooperação como ferramenta para o desenvolvimento da capacitação científica, resultando em benefícios para ambos os partícipes dos projetos. A cooperação científica entre os países doadores e os receptores e os padrões e modelos de financiamento demandam instituições fortes nos países receptores, capazes não só de formular as agendas e demandas, mas de perceber os resultados das pesquisas como o produto da interação entre distintos atores (governo, agências internacionais, organizações não-governamentais, pesquisadores) (Velho, 1997). Pode-se sugerir que as agências de cooperação internacional - tanto as mais "antigas", como a Ford e a Rockefeller, como as ONGs dos tempos atuais (muitas delas auxiliadas por aquelas fundações, deve-se lembrar aqui) - têm mudado seus estilos de atuação, democratizando as regras e contratos que envolvem as relações de cooperação entre países industrialmente avançados e os periféricos. Segundo outros autores, essas agências estão cada vez mais buscando parcerias não apenas com cientistas, universidades e centros de pesquisa, mas com organizações comunitárias e movimentos sociais nos vários países assistidos (Bezanson e Oldham, 2000).

(Recebido para publicação em outubro de 2005)

(Versão definitiva em março de 2006) 


\section{NOTAS}

1. É conhecida a contribuição de Simon Schwartzman $(1979 ; 2001)$ ao estudo da formação da comunidade científica no Brasil. Um Espaço para a Ciência (nova versão de Formação da Comunidade Científica no Brasil) mantém o capítulo sobre a atuação da Fundação Rockefeller e o apoio financeiro à ciência profissional no Brasil. Entretanto, a edição recente, de 2001, no capítulo sobre a Rockefeller, deixou de rever algumas interpretações e, particularmente, manteve dados estatísticos que necessitam de correção. Quanto aos dados históricos e estatísticos, a Fundação Rockefeller foi oficialmente fundada em 1913 e não em 1909, como indica o texto. Uma segunda imprecisão diz respeito ao apoio da Fundação à área médica. De acordo com um quadro de dotações da Rockefeller para pesquisa e ensino superior no país (ver p. 247 da nova versão), a área médica brasileira só teria recebido apoio a partir da década de 1950, juntamente com as Ciências Naturais e a Agricultura. Dados colhidos no Rockefeller Archive Center, nos Estados Unidos, indicam, no entanto, o apoio à área médica no Brasil, desde inícios da década de 1920. Já nos primeiros anos da presença da Fundação no Brasil, e particularmente a partir dos anos de 1920, foram concebidas bolsas de estudos para cientistas brasileiros, não só no campo da saúde pública, mas também no da medicina. Ver The Rockefeller Directory of Fellowship Awards. "Roster of Fellows and Scholars, 1917-1950", Relatório Anual, 1950. Além do apoio a bolsistas, a Faculdade de Medicina e Cirurgia de São Paulo recebeu, entre os anos de 1916 e 1931, apoio institucional e financeiro (ver Marinho, 2003). Finalmente, parece-nos difícil sustentar que o padrão norte-americano de ensino e pesquisa tenha sido, como sugere Schwartzman (2001:247), "simplesmente copiado o mais proximamente possível, para servir de modelo a ser seguido". A nosso ver, não se deu uma relação de "cópia" ou importação passiva, mesmo porque as tradições francesa e alemã já eram parte de nossa herança científica "na periferia", quando aqui chegaram os pesquisadores norte-americanos. Para uma análise dessas questões (naturalmente sujeitas a interpretações distintas), ver Castro Santos e Faria (2003).

2. Em relação ao Brasil, por exemplo, os acordos de cooperação realizados entre a Fundação Rockefeller e os governos dos estados brasileiros, entre as duas grandes guerras, tiveram que passar pela aprovação e consentimento do Governo Federal. No caso brasileiro, também, existia autonomia do pesquisador na definição de objetos de pesquisa, ainda que houvesse certa delimitação de campo temático.

3. Em trabalhos anteriores, discutimos a atuação da Fundação Rockefeller no Brasil: as parcerias que estabeleceu com cientistas e sanitaristas brasileiros, o apoio às campanhas de combate à ancilostomíase, à malária e à febre amarela, a cooperação na área de saúde pública etc. Para um estudo aprofundado sobre a atuação da Fundação Rockefeller no Brasil e em outros países, ver: Collier e Horowitz, 1976; Howe, 1982; Marinho, 2001; Cueto, 1994; Castro Santos e Faria, 2003.

4. Ver Rockefeller Foundation, Relatório Anual, 1920.

5. Ver The Rockefeller Directory of Fellowship Awards. "Roster of Fellows and Scholars", 1917-1950, 1950. Ver também Rockefeller Archive Center, "Súmula do Presidente, extraída do relatório anual da Fundação Rockefeller 1954/1955", 1956.

6. Para um estudo sobre a Faculdade de Medicina e Cirurgia de São Paulo, ver " 25 anos de atividades - A Faculdade de Medicina da Universidade de São Paulo festeja hoje o 
25ํaำersário de sua instalação". Inventário Capanema, GC 38. 04. 02, Doc. 140, CPDOC. Ver também Candeias (1984) e Marinho (2001).

7. Sobre a trajetória histórica do Instituto de Higiene de São Paulo, ver Candeias (1984); Faria (1999); Campos (2002). Outras instituições que receberam recursos humanos e financeiros da Fundação Rockefeller entre os anos de 1916 e 1950, ver Anexo I.

8. Sobre a Escola Anna Nery, consulte-se Barreira (1975) e Barreira e Santos (1999).

9. Para um estudo da cooperação da Fundação Rockefeller com a Universidade de São Paulo, ver Marinho (2001).

10. O fechamento do escritório da Rockefeller na Alemanha e as dificuldades enfrentadas pela China - mergulhada em uma guerra civil - contribuíram para o aumento do leque de interesses da instituição norte-americana na região. Neste período, a Rockefeller reorganiza a International Health Division - IHD, criando ou reorganizando escritórios nas principais capitais latino-americanas. Entre os mais importantes estavam o Escritório de Buenos Aires e o Escritório do Rio de Janeiro (ver Costa, 2004).

11. A mudança para a área de ciências naturais não deve ser vista, comprovadamente, como uma questão política, ainda que se possa sugerir as dificuldades de um campo como a saúde pública, muito mais afeito à "politização" do que, por exemplo, uma pesquisa sobre milho híbrido. Tudo indica que a área de saúde pública não estava dando bons rendimentos, ao contrário da área de genética, por exemplo. É certo que não houve na saúde pública o sucesso esperado.

12. Professor de Agricultura, Escola Superior de Agricultura Luiz de Queiroz, em Piracicaba.

13. Professores de Zootecnia, Escola Superior de Agricultura Luiz de Queiroz, em Piracicaba.

14. Carlos Krug especializou-se em genética na Universidade de Cornell, nos Estados Unidos.

15. Formado em botânica na Universidade de Breslau. Em 1924, recebeu uma bolsa de estudos da Fundação Rockefeller na Universidade de Harvard. Depoimentos CPDOC/FGV: História Oral, 1985, 156 p. História da Ciência, Finep/CPDOC.

16. Em 1937, assumiu o cargo de professor catedrático de Biologia Geral da Faculdade de Filosofia, Ciências e Letras da USP. Foi um especialista renomado na área da Genética (ver Lacaz, 1963).

17. Biólogo russo que emigrou para os Estados Unidos na década de 1920.

18. Nas décadas de 1970, 1980 e 1990, a Rockefeller continuou apoiando programas na área da agricultura, mas direcionou sua atenção, também, para projetos de preservação do meio ambiente, por meio de promoção de desenvolvimento sustentável e formação de recursos humanos.

19. Entre os anos de 1954 e 1983, o Population Council financiou o Programa "População", que tinha como uma de suas metas criar e aprimorar métodos contraceptivos. Ver Rockefeller Foundation, Relatório Anual, 2003.

20. Empresas pertencentes à família Rockefeller, além do Laura Spelman Rockefeller Memorial: Spelman Fund of New York (1928); Davison Fund (1930); Rockefeller Center (1939); Rockefeller Brothers Fund (1940).

21. Em valores constantes de 1959. 
22. Industrial norte-americano, nascido em Detroit em 1863. Em 1896, fabricou seu primeiro automóvel e três anos depois fundou, em sociedade com dois amigos, a Detroit Automobile Co., que teve duração de um ano. Em 1903, fundou a Ford Motor Company, com recursos próprios. Dez anos depois, as linhas de montagem da Ford produziam um carro a cada 15 segundos. Henry Ford sempre demonstrou interesse pela agricultura. No Brasil, obteve a concessão de uma vasta região da Amazônia, que ficou conhecida como "Fordlândia", onde tentou desenvolver plantações racionais de seringueiras. Henry Ford faleceu em 1947, deixando grande parte de sua fortuna para a Ford Foundation (ver Nielsen, 1996).

23. A Fundação Ford não mais possui ações da Companhia Ford. Seus investimentos são administrados para ser uma fonte permanente de recursos para custear seus programas (ver Ford Foundation, Relatório Anual, 2003; 2004).

24. Ver também Berresford(2005).

25. Ver o site www.fordfound.org/global/office/index, último acesso em 20 de setembro de 2004.

26. Segundo Mello e Souza, o apoio da Ford à área da reprodução no Brasil "foi decisivo para o desenvolvimento do campo da demografia, de programas de planejamento familiar, do conhecimento biomédico sobre reprodução e, conseqüentemente, para a promoção do debate público sobre políticas populacionais". Ainda segundo Mello e Souza, entre 1992 e 2002, a Ford desembolsou cerca de US\$2,5 milhões para financiar o Programa de Pesquisa e Formação em Saúde Reprodutiva e Sexualidade do Núcleo de Estudos Populacionais - Nepo, vinculado à Unicamp. No início de 2000, o Programa havia formado 160 profissionais e pesquisadores (Mello e Souza, 2002:131-164).

27. Estas áreas fazem parte de três grandes Programas da Fundação Ford: "Asset Building \& Community Development" (Economic Development, Community \& Resource Development);"Peace \& Social Justice" (Human Rights; Governance \& Civil Society); "Knowledge, Creativity \& Freedom" (Education, Sexuality, Religion; Media, Arts \& Culture) (ver Ford Foundation, Relatório Anual, 2004; 2005).

28. São eles: Nova York, cidade do México, Rio de Janeiro, Santiago, Moscou, Cairo, Lagos, Nova Delhi, Nairobi, Johannesburgo, Jacarta, Hanói, Beijing. Em 2004, a Ford abriu mais dois escritórios (Warsaw e Jerusalém).

29. Ver, no Anexo II, os maiores donatários da Fundação Ford no Brasil de acordo com o total de doações recebidas (em dólares de 2001).

30. Depoimento de Luiz Antonio de Castro Santos, Pesquisador-Sênior do Cebrap, entre 1985 e 1990, e membro de sua diretoria, em 1988/1989. Entrevista concedida em novembro de 2005, Rio de Janeiro.

31. Empresa criada em 1928 e financiada pela Fundação Rockefeller, ver nota 20.

32. Em 1889, a família Rockefeller ajudou a criar a Universidade de Chicago. Até 1910, foram doados cerca de US\$ 35 milhões para a instituição.

33. Este novo ramo da administração pública foi incorporado, também, pelo Laura Spelman Rockefeller Memorial, criado em 1918. No início das atividades, o Laura Spelman contribuiu com cerca de US\$10 milhões para projetos nesta área. Ver página 169 deste texto.

34. Para um estudo mais aprofundado sobre o apoio da Fundação Ford à área de administração pública no Brasil, ver Station e Welna (2002). 
35. Conforme sugestão do trabalho clássico de Hirschman (1971).

36. Em trabalho recente (Castro Santos e Faria, 2003), procuramos aprofundar essa análise.

37. Nelson Rockefeller foi assessor especial para a América Latina desde o final da década de 1940 até a década de 1970.

\section{REFERÊNCIAS BIBLIOGRÁFICAS}

ADORNO, Sérgio e CÁRDIA, Nancy. (2002), “Das Análises Sociais aos Direitos Humanos". Os 40 anos da Fundação Ford no Brasil. São Paulo/Rio de Janeiro, Editora da Universidade de São Paulo/Fundação Ford, pp. 201-240.

ARNOVE, Robert F. (1980), Philanthropy and Imperialism: The Foundations at Home and Abroad ( $2^{\mathrm{a}}$ ed.). Bloomington, Indiana University Press.

BARREIRA, Ieda de Alencar. (1975), “Estudo Exploratório sobre a Consulta de Enfermagem". Revista Brasileira de Enfermagem, no 28, pp. 76-94.

eSANTOS, Tânia Cristina Franco. (1999), “A Escola Anna Nery como Centro Difusor de Tradições Nativas". Escola Anna Nery. Revista de Enfermagem, vol. 3, no 2, pp. 18-33.

BERRESFORD, Susan V. (2005), “Taking a Long View. The Roots and Mission of the Ford Foundation". Relatório Anual, Ford Foundation.

BEZANSON, K. e OLDHAM, G. (2000), Issues and Options Concerning a European Foundation for Research for Development. Brighton, UK, Institute of Development Studies. Manuscrito, pp. 1-51.

BRANDÃO LOPES, Juarez Rubens. (1993), “Trinta Anos da Fundação Ford no Brasil: Um Testemunho com alguma Análise", in S. Miceli (coord.), A Fundação Ford no Brasil. São Paulo, Editora Sumaré/FAPESP, pp. 155-163.

BROOKE, Nigel. (2002), “O Escritório da Fundação Ford no Brasil, 1962-2002: Um Apanhado Histórico", in N. Brooke e M. Witoshynsky (orgs.), Os 40 Anos da Fundação Ford no Brasil: Uma Parceria para a Mudança Social. São Paulo/Rio de Janeiro, Editora da Universidade de São Paulo/Fundação Ford, pp. 245-284.

CAMPOS, Cristina de. (2002), São Paulo pela Lente da Higiene. As Propostas de Geraldo de Paula Souza para a Cidade (1925-1945). São Carlos, RiMa Editora.

CAMPOS, Maria Malta. (2002), “Da Formação de Professores de Ciências à Reforma da Educação", in N. Brooke e M. Witoshynsky (orgs.), Os 40 Anos da Fundação Ford no Brasil: Uma Parceria para a Mudança Social. São Paulo/Rio de Janeiro, Editora da Universidade de São Paulo/Fundação Ford, pp. 97-127.

COLLIER, Peter e HOROWITZ, David. (1976), The Rockefellers: An American Dynasty. Broadway, New York, New American Library, pp. 61-65. 
CANDEIAS, Nelly M. Ferreira. (1984), “Memória Histórica da Faculdade de Saúde Pública da Universidade de São Paulo (1918/1954)". Revista de Saúde Pública, vol. 18, número especial, pp. 2-60.

CASTRO SANTOS, Luiz A. de. (1989), “A Fundação Rockefeller e o Estado Nacional (História e Política de uma Missão Médica e Sanitária no Brasil)". Revista Brasileira de Estudos da População, vol. 6, nº 1, pp. 105-110.

. (2004), “A Cooperação Internacional e a Enfermagem de Saúde Pública no Rio de Janeiro e São Paulo". Horizontes, vol. 22, no 2, pp. 123-148.

e FARIA, Lina R. de. (2003), A Reforma Sanitária no Brasil: Ecos da Primeira República. São Paulo, Editora da Universidade São Francisco.

CASTROSANTOS, Luiz A. de e MARINHO, M. G. (eds.). (2004), “Editorial”. Horizontes, vol. 22, nํㅡ, pp. 121-122.

COSTA, Maria da Conceição da. (2004), “Cooperação Internacional, Desenvolvimento e Ciência na Periferia". Horizontes, vol. 22, nํ2, pp. 191-204.

CUETO, Marcos. (1992), Ciencia y Filantropia en las Américas. Conferência proferida no III Congresso Latino-Americano de História da Ciência e da Tecnologia, Cidade do México.

. (1994), "Introduction" in M. Cueto (ed.), Missionaries of Science. The Rockefeller Foundation and Latin America. Indiana University Press, Bloomington/Indianápolis.

FARIA, Lina R. de. (1999), “O Instituto de Higiene: Contribuição à História da Ciência e da Administração em Saúde em São Paulo". Physis - Revista de Saúde Coletiva, vol. IX, nº 1, pp. 175-208.

FITZGERALD, Deborah. (1994), “Exporting American Agriculture: The Rockefeller Foundation in México, 1943-1953", in M. Cueto (ed.), Missionaries of Science. The Rockefeller Foundation and Latin America. Bloomington/Indianápolis, Indiana University Press, pp. 72-96.

GLICK, Thomas F. (1994), "The Rockefeller Foundation and the Emergence of Genetics in Brazil.1943-1960", in M. Cueto (ed.) Missionaries of Science. The Rockefeller Foundation and Latin America. Bloomington/Indianápolis, Indiana University Press, pp. 149-164.

HIRSCHMAN, Albert O. (1971), A Bias for Hope. New Haven/London, Yale University Press.

HOWE, Barbara. (1982), “The Emergence of Scientific Philanthropy, 1900-1920: Origins, Issues and Outcomes", in R. F. Arnove (ed.), Philanthropy and Cultural Imperialism: The Foundations at Home and Abroad ( $2^{\mathrm{a}}$ ed.). Bloomington, Indiana University Press, pp. 25-54.

JAGUARIBE, Hélio. (1967), Problemas do Desenvolvimento Latino-Americano. Estudos de Política. Rio de Janeiro, Civilização Brasileira.

LACAZ, Carlos da Silva. (1963), Vultos da Medicina Brasileira. São Paulo, Ed. Helicon.

MARINHO, Maria Gabriela S. M. C. (2001), Norte-Americanos no Brasil. Uma História da Fundação Rockefeller na Universidade de São Paulo (1934-1952). Campinas/São Paulo, Autores Associados/Universidade São Francisco. 
. (2003), Elites em Negociação: Breve História dos Acordos entre a Fundação Rockefeller e a Faculdade de Medicina de São Paulo (1916-1931). Bragança Paulista, EDUSF.

MELLO E SOUZA, Cecília de. (2002), “Dos Estudos Populacionais à Saúde Reprodutiva", in N. Brooke e M. Witoshynsky (orgs.), Os 40 Anos da Fundação Ford no Brasil. Uma Parceria para a Mudança Social. São Paulo/Rio de Janeiro, Editora da Universidade de São Paulo/Fundação Ford, pp. 355-386.

MICELI, Sérgio (coord.). (1993), A Fundação Ford no Brasil. São Paulo, Editora Sumaré/FAPESP.

NIELSEN, Waldemar A. (1996), Inside American Philanthropy: The Dramas of Donorship. Norman/London, University of Oklahoma Press.

ROCKEFELLER, David. (2003), Memórias. Rio de Janeiro, Rocco (tradução de Ryta Vinagre).

SAUNIER, Pierre-Yves. (2000), "Selling the Idea of Cooperation". The US Foundations and the European Components of the "Urban Internationale" 1920s-1960s. Lyon, l'Université Lumière-Lyon. Manuscrito, pp. 1-24.

SCHWARTZMAN, Simon. (1979), Formação da Comunidade Científica no Brasil. São Paulo/Rio de Janeiro, Editora Nacional/Finep.

. (2001), Um Espaço para a Ciência. A Formação da Comunidade Científica no Brasil. São Paulo/Rio de Janeiro, Editora Nacional/FINEP.

STATION, Elizabeth e WELNA, Christopher J. (2002), “Da Administração Pública à Participação Democrática", in N. Brooke e M. Witoshynsky (orgs.), Os 40 Anos da Fundação Ford no Brasil. São Paulo/Rio de Janeiro, Editora da Universidade de São Paulo/Fundação Ford, pp. 167-197.

VELHO, Lea Maria Leme Strini. (1997), Cooperação em Ciência e Tecnologia no Mercosul. Brasília, OEA/MCT, Relatório de pesquisa. pp. 1-50.

VILLAR, Mauro. (1964), “Fundações”. Enciclopédia Barsa. Rio de Janeiro, Encyclopaedia Britannica Editores, Ltda. 


\section{ANEXO I}

\section{Alguns donatários da Fundação Rockefeller no Brasil}

Escola Superior de Agricultura

Escola Superior de Agricultura de Viçosa

Escola de Economia Doméstica

Escola Superior de Agricultura de Minas Gerais

Escola Anna Nery

Faculdade de Saúde Pública da USP

Faculdade de Medicina e Cirurgia de São Paulo

Faculdade de Medicina de São Paulo

Faculdade de Medicina do Rio de Janeiro

Faculdade Paulista de Medicina

Faculdade de Medicina de Ribeirão Preto

Instituto Oswaldo Cruz

Instituto Evandro Chagas

Instituto de Higiene de São Paulo

Instituto Biológico de São Paulo

Instituto de Biologia e Pesquisas Tecnológicas do Paraná

Instituto Agronômico de Belo Horizonte

Instituto Agronômico do Sul

Instituto Agronômico do Norte

Instituto Agronômico de Campinas

Instituto Biológico da Bahia

Instituto Biológico de Curitiba

Universidade Federal do Rio Grande do Sul

Universidade Federal de Minas Gerais

Universidade Federal do Ceará

Universidade do Paraná

Universidade Estadual de Campinas

Universidade de São Paulo

Faculdade de Veterinária e Instituto Agronômico da UFRRJ

Laboratório de Microbiologia da Universidade do Brasil

Universidade da Bahia

Fonte: "Photograph Collection, Series Report - Rockefeller Foundation Photos", Rockefeller Archive Center, 2005.

Obs: Mantivemos as denominações originais das instituições na época em que foram agraciadas pela Fundação Rockefeller. 


\section{ANEXO II}

\section{Alguns donatários da Fundação Ford no Brasil*}

Universidade de São Paulo

Universidade Federal do Rio de Janeiro

Fundação Getulio Vargas

Sociedade Brasileira de Instrução

Universidade Federal de Viçosa

Universidade Federal de Minas Gerais

Universidade Federal da Bahia

Universidade Federal do Ceará

Universidade de Brasília

Fundação Carlos Chagas

Coordenação do Aperfeiçoamento de Pessoal de Nível Superior

Pontifícia Universidade Católica do Rio de Janeiro

Universidade Federal do Paraná

Sociedade Civil Bem-Estar da Família no Brasil

Escola Técnica Federal Celso Suckow da Fonseca (atual Cefet/RJ)

Universidade Federal de Pernambuco

Universidade Federal do Rio Grande do Sul

Universidade Estadual de Campinas

Universidade Estadual do Rio de Janeiro

Estados Unidos do Brasil

Centro Brasileiro de Análise e Planejamento

Governo do Estado de Minas Gerais

Fundação Brasileira para o Desenvolvimento do Ensino da Ciência

Centro de Estudos de Cultura Contemporânea

Pontifícia Universidade Católica do Rio Grande do Sul

Instituto de Estudos Econômicos, Sociais e Políticos de São Paulo

Centro de Estudos e Pesquisa em Saúde Coletiva

Associação Nacional de Pós-Graduação e Pesquisa em Ciências Sociais

Banco Nacional de Desenvolvimento Econômico e Social

Geledés - Instituto da Mulher Negra

Instituto Universitário de Pesquisas do Rio de Janeiro

Centro Feminista de Estudos e Assessoria

Associação Brasileira de Estudos Populacionais

Pontifícia Universidade Católica de São Paulo

Fundação Universidade Federal do Acre

Instituto Brasileiro de Administração Municipal

Instituto Socioambiental 
Associação Nacional dos Centros de Pós-Graduação em Economia Centro de Cultura Luiz Freire Associação Brasileira Interdisciplinar de Aids Instituto de Estudos, Formação e Assessoria em Políticas Sociais Instituto do Homem e Meio Ambiente da Amazônia Conselho Nacional de Desenvolvimento Científico e Tecnológico Laspau: Programas Acadêmicos e Profissionais para as Américas Instituto de Estudos Socioeconômicos

Instituto Brasileiro de Análises Sociais e Econômicas

Universidade Federal do Pará

Universidade Federal de Juiz de Fora

Secretaria de Agricultura do Estado de São Paulo

Fonte: Ford Foundation, Relatório Anual, 2002; 2004; 2005.

*Algumas doações recentes incluem: Centro de Cultura Negra do Maranhão (CCN), para a promoção dos direitos da saúde sexual e reprodutiva em centros religiosos afro-brasileiros; Universidade Federal de Rondônia, para promoção de pesquisa aplicada sobre a saúde reprodutiva das populações indígenas do estado de Rondônia; o Centro Nordestino de Medicina Popular, para treinamento de agentes locais de saúde; Fundação Oswaldo Cruz, também para treinamento de agentes locais de saúde e o Centro Latino-Americano em Sexualidade e Direitos Humanos do Instituto de Medicina Social da Universidade do Estado do Rio de Janeiro. 


\begin{abstract}
International Scientific Cooperation: Styles of Action Adopted by the Rockefeller and Ford Foundations
\end{abstract}

International nonprofit foundations are acknowledged for their role in supporting scientific research, training human resources (physicians, public health professionals, and nurses), and creating science institutions and health services in developing countries. Focusing on the work of foreign institutions like the Rockefeller and Ford Foundations, the current study aims to highlight several innovative and pioneering initiatives, considering their areas of action, priorities, diversification of activities, changes in guidelines, and partnerships with international and Brazilian institutions during the Pre- and Post-War periods. The study also analyzes how these foundations readjust their agendas as a function of the presence of new players, institutions, and objectives.

Key words: international scientific cooperation; Rockefeller Foundation; Ford Foundation; scientific philanthropy; science models; human resources training

\title{
RÉSUMÉ
}

Coopération Scientifique Internationale: Mode d'Action de la Fondation Rockefeller et de la Fondation Ford

On reconnaît que les fondations philanthropiques internationales ont joué un rôle important d'appui à la recherche scientifique, d'aide à la formation de ressources humaines (médecins, personnel de la santé publique, infirmiers) ainsi qu'à la création d'institutions de science et de services de santé dans les pays en voie de développement. Dans cet article, on examine l'action d'institutions étrangères telles la Fondation Rockefeller et la Fondation Ford afin de relever quelques initiatives novatrices, compte tenu des domaines d'action, des priorités, de la diversification des activités, des changements d'orientation et des partenariats avec des institutions nationales et internationales, dans la période de l'entre-deux-guerres et de l'après-guerre. Tout cela afin de comprendre la façon dont ces fondations ont réajusté leurs programmes face à de nouveaux acteurs, institutions et objectifs.

Mots-clé: coopération scientifique internationale; Fondation Rockefeller; Fondation Ford; philanthropie scientifique; modèles de science; formation de ressources humaines 